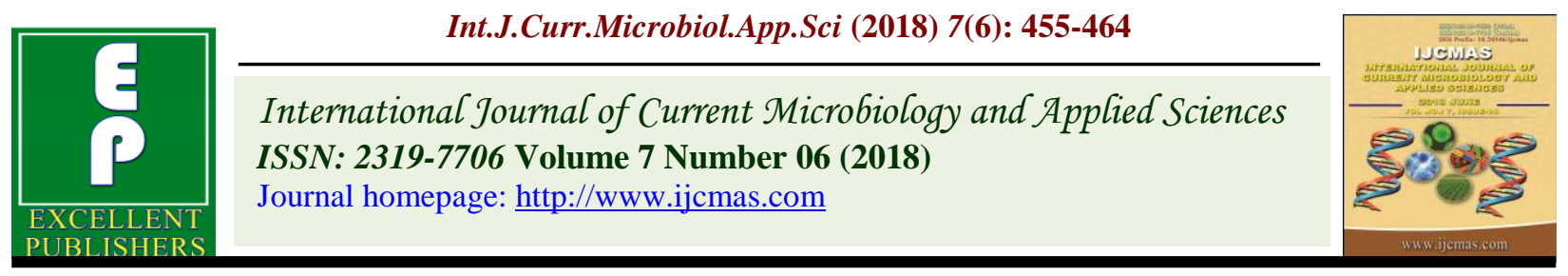

Original Research Article

https://doi.org/10.20546/ijcmas.2018.706.051

\title{
Testicular Volume, Seminal Attributes and Body condition score in Infertile Dogs
}

\author{
I. Shalini*, D. Antoine, K. Murugavel, S. Kantharaj and M.S. Raju \\ Department of Veterinary Gynaecology and Obstetrics, Rajiv Gandhi Institute of Veterinary \\ Education and Research, Puducherry - 605009, India
}

\begin{tabular}{|l|}
\hline K e y w o r d s \\
$\begin{array}{l}\text { Aspermia, Azoospermia, } \\
\text { Hypokinozoospermia, } \\
\text { Oligozoospermia, Poor } \\
\text { membrane integrity, } \\
\text { Semen collection, } \\
\text { Testicular degeneration }\end{array}$ \\
\hline Article Info \\
\hline $\begin{array}{l}\text { Accepted: } \\
\text { 04 May 2018 } \\
\text { Available Online: } \\
\text { 10 June } 2018\end{array}$ \\
\hline
\end{tabular}

\section{Introduction}

A rapid, reliable and cost effective treatment to predict ovulation time by vaginal cytology is widely practiced to fix breeding date. In spite of fixing breeding date by different methods like Exfoliative Vaginal Cytology, Blood progesterone estimation, Vaginoscopy, a wide spread apparent infertility in dogs has been reported by pet owners and dog breeders. Reduced fertility and fecundity in dog results in substantial financial losses to the canine breeding industry. In this context recently canine semen has been attracting attention by
The six different breeds of dogs were selected for Breeding Soundness Examination. The testes were soft in texture and no other scrotal abnormality was noticed. Body condition score was evaluated on a scale of 1-9 and Testicular volume was measured by Vernier caliper before semen collection. Semen was collected by digital manipulation. The biophysical and biochemical characteristics of semen were analyzed. The body condition score, testicular volume, volume of semen, colour, $\mathrm{pH}$, mass activity, initial motility, sperm concentration, live spermatozoa, total sperm abnormality, Intact acrosome and positive for HOS were $4.80 \pm 0.32,23.4 \pm 1.94 \mathrm{~cm}^{3}, 3.90 \pm 0.42 \mathrm{ml}$, Opalescent/clear, 6.12 $38.3 \pm 4.58 \%$ and $35.2 \pm 4.67 \%$, r $110 \pm 18.52$ millions $/ \mathrm{ml}, 70.2 \pm 2.60 \%, 11.1 \pm 2.06 \%$, and ACP were $2.47 \pm 0.29 \mathrm{~g} / \mathrm{dl}, 0.28 \pm 0.05 \mathrm{~g} / \mathrm{dl}, 1.96 \pm 0.24 \mathrm{~g} / \mathrm{dl}, 1904 \pm 329 \mathrm{IU} / \mathrm{L}$ and $925 \pm 79.0 \mathrm{IU} / \mathrm{L}$, respectively. The major poor semen quality parameters in this study were oligozoospermia, hypokinozoospermia, azoospermia, aspermia, testicular degeneration, poor membrane integrity, poor secretary functions of the epididymis and prostate gland. In the present study all the nine dogs were infertile. 
live and dead spermatozoa and sperm morphology in the whole ejaculate are frequently examined to assess the quality of semen (Silva et al., 2005). The functional integrity of the sperm plasma membrane is crucial for the viability and fertilizing ability of spermatozoa (Hafez, 1993). The determination of intact acrosome is another essential tool to evaluate indirectly the fertilizing capacity of spermatozoa (Wells and Awa, 1970). The seminal plasma enzyme, alkaline phosphatase is primarily of testicular and epididymal origin. Alkaline phosphatase level is often used for the diagnosis of oligozoospermia, azoospermia and incomplete ejaculation (Schafer-Somi et al., 2013). Another seminal plasma enzyme, the acid phosphatase is a biochemical marker, primarily related to the metabolic functions of spermatozoa and prostate diseases in dogs (King and Macpherson, 1966). The objective of this study, all the different breeds of dogs was screened for BSE and all the semen quality measures comparable to other reports on the fertile dog semen.

\section{Materials and Methods}

\section{Experimental animals}

The six different breeds of dogs aged between 2-6 years maintained by dog breeders and pet owners of Puducherry were selected for Breeding Soundness Examination. The six different breeds of dogs comprised of GSD, Labrador, Pug, Cocker spaniel, Golden Retriever and Spitz. All the dogs were apparently healthy and they were fed twice a day with commercial dry dog food and had ad libitum access to water.

\section{Body condition score}

Body Condition Score (BCS) on a scale of 1 to 9 was assessed before semen collection as per the method described by Laflamme
(1997). The mid-range in the scale represented optimal body condition, lower values indicated lean to emaciated conditions and higher value to excessive body fat.

\section{Testicular volume}

The measurement of testicular dimensions (length, width and height) provides an accurate assessment of canine testicular volume. The testicular volume was measured as per Vernier caliper method and as per the formula adopted by Harriet et al., (2002).

\section{Semen collection}

Semen was collected by digital manipulation and stimulation of the Bulbus glandis (LindeForsbrg, 2005a). The whole ejaculates (including pre-sperm, sperm rich and post sperm) were collected in sterile graduated measuring plastic tube. Immediately the collected semen was brought to the laboratory in a transport container. Sufficient care was taken to ensure that the semen was not exposed to unfavourable conditions during and after collection. The first semen collection was used as test trial and not included in the analysis of data and subsequently the semen was collected at weekly interval for six consecutive weeks and subjected to semen evaluation. A total of 37 ejaculates from nine dogs were subjected to semen analysis. During the study period the selected dogs was not subjected to additional semen collection or natural service.

\section{Volume and colour of the ejaculate}

A glass funnel fitted in a graduated measuring plastic tube was used to collect the ejaculate and the volume was directly measured on the graduated marks in the measuring tube (LindeForsberg, 1995). The colour was visually noticed as per the method described by (Feldman et al., 2004). 


\section{pH and mass activity}

The $\mathrm{pH}$ of dog semen was measured by $\mathrm{pH}$ paper in the $\mathrm{pH}$ range from 5.0-8.0 (Freshman, 2002). The mass activity of spermatozoa was recorded immediately after semen collection by examining a drop of semen on a clean glass slide at 100x magnification without cover slip. Mass activity was evaluated on a scale of 0-5 as per the method described by Evans and Maxwell (1987).

\section{Initial motility}

The initial motility of spermatozoa was recorded immediately after semen collection by examining a drop of semen on a clean glass slide and diluted with one drop of Tris buffer kept at $37^{\circ} \mathrm{C}$ at $400 \mathrm{x}$ magnification with a coverslip. The initial motility was evaluated as per the method described by Gunzel-Apel (1994) and Feldman and Nelson (1996).

\section{Sperm concentration}

Sperm concentration was calculated by haemocytometric method (Sorenson, 1976) and expressed in millions of spermatozoa per milliliter of semen. A small volume of semen (20 microliters) was added to a known volume of formalin based fluid to kill the sperm and aknown volume of this fluid is applied to a counting chamber in the haemocytometer. The counting chamber's grid under a microscope at $400 \mathrm{x}$ magnification, the numbers of spermatozoa were counted to determine the concentration per milliliter of semen.

\section{Live and Dead spermatozoa}

Nigrosin-eosin staining technique (Hancock and Rowlands, 1949) was adopted to identify the live and the dead spermatozoa. A total of 200 spermatozoa counted in randomly selected microscopic fields and the percentage of live spermatozoa was calculated.

\section{Sperm abnormality}

The sperm morphology was studied using nigrosin-eosin stained semen smear. A total of 200 sperms will be observed in not less than 10 randomly selected microscopic fields per sample under 1000x magnification.

The percentage of abnormal sperm with head abnormality, proximal and distal protoplasmic droplet, deformed tail and total number of abnormal sperm were calculated.

\section{Membrane integrity}

\section{Hypo-Osmotic Swelling Test (HOST)}

The sperm plasma membrane integrity was assessed as per the method described by Lomeo and Giambersio (1991). A volume of $10.0 \mu \mathrm{l}$ of semen was added to $1 \mathrm{ml}$ of mono distilled water and incubated at $37^{\circ} \mathrm{C}$ for 5 min. After incubation, 1 drop of the semen was placed on a glass slide covered with cover slip and evaluated under 1000x magnification. A total of 200 sperms were evaluated and percentages of swollen tail spermatozoa were calculated.

\section{Acrosome membrane integrity}

Acrosomal cap integrity by using Giemsa stain was studied as per the method adopted by Watson (1975). The acrosome morphology was classified as intact (Plate 5), partial and completely lost acrosome as per the classification of Blom (1972).

\section{Biochemical constituents in canine seminal plasma}

The semen collected was centrifuged at 1000x $\mathrm{g}$ for $15 \mathrm{~min}$ at room temperature. The separated seminal plasma was centrifuged at $10,000 \mathrm{x} g$ for $10 \mathrm{~min}$ at room temperature and stored at $-80^{\circ} \mathrm{c}$ (Strzezek et al., 2015). The separated seminal plasma was used for 
estimation of biochemical constituents.

\section{Estimation of total protein, albumin and globulin}

The total protein and albumin in the seminal plasma was estimated by colorimetric method (Doumas et al., 1977). The diagnostic kits of Beacon diagnostic was used for estimating the concentration of total protein and albumin expressed in $\mathrm{mg} / \mathrm{ml}$ by using a $\mathrm{A}_{5}{ }_{4}{ }_{6} \mathrm{~nm}$ for total protein and $A_{6} 30 \mathrm{~nm}$ for total albumin. The total globulin $(\mathrm{G})$ concentration was calculated based on the difference between seminal plasma total protein and seminal plasma albumin.

Estimation of alkaline and acid phosphatase

The concentration of alkaline phosphatase (Bessey et al., 1946) and acid phosphatase enzymes were estimated by colorimetric method $\mathrm{A}_{4} 0_{5}{ }_{5} \mathrm{~nm}$ by using the diagnostic kits.

\section{Statistical analysis}

The data generated through semen evaluation in different breeds of dogs was analyzed statistically by One-way ANOVA followed by turkey test by using the Graph pad prism version 5 .

\section{Results and Discussion}

The nine infertile dogs comprised of GSD (n:1), Labrador (n:2), Pug (n:3), Cocker spaniel (n:1), Golden Retriever (n:1) and Spitz (n:1). The mean \pm SE for age was $3.55 \pm 0.50$. A total of 37 ejaculates were analyzed and compared with fertile dog semen. For infertile dogs, the data generated for BCS, testicular volume, biophysical and biochemical constituents of semen were analyzed and compared with fertile dogs.

\section{Breeding soundness examination}

\section{Biophysical characteristics of semen}

The mean body condition score for infertile dogs was $4.80 \pm 0.32$. The testicular volume was $23.4 \pm 1.94 \mathrm{~cm}^{3}$ (Fig. 1), volume of the ejaculate $3.90 \pm 0.42 \mathrm{ml}$ and the $\mathrm{pH}$ of semen was $6.12 \pm 0.06$ for infertile dogs. The mass activity (2.58 \pm 0.11$)$, initial motility $(54.8 \pm 4.39 \%)$, sperm concentration $(110 \pm 18.52$ millions $/ \mathrm{ml})$ and the incidence of percentage of live spermatozoa $(70.2 \pm 2.60 \%)$ were low in infertile compared to fertile dog semen. The total sperm abnormality was $11.1 \pm 2.06 \%$ in infertile dogs. The mass activity (2.58 \pm 0.11$)$, initial motility $(54.8 \pm 4.39 \%)$, sperm concentration $(110 \pm 18.52$ millions $/ \mathrm{ml})$ and the incidence of percentage of live spermatozoa $(70.2 \pm 2.60 \%)$ were low in different breeds of dogs comparable with other reports on fertile dog semen. The total sperm abnormality was $11.1 \pm 2.06 \%$ in dogs (Table 1).

\section{Sperm membrane integrity}

\section{Acrosome membrane integrity}

The percentage of incidence of intact acrosome was $38.3 \pm 4.58 \%$ and the HOS positive spermatozoa were $35.2 \pm 4.67 \%$ for dogs. The acrosome integrity was classified as intact acrosome, partially lost acrosome and completely lost acrosome were $38.3 \pm 4.58 \mathrm{Vs}$ $79.2 \pm 0.63 \%, 23.9 \pm 3.48$ Vs $13.6 \pm 0.62 \%$ and $37.7 \pm 4.47 \mathrm{Vs} 7.47 \pm 0.49 \%$, respectively (Table 1). The percentage of intact acrosome was significantly low in the present study compared to other reports on fertile dog semen.

\section{Hypo Osmotic Swelling Test (HOST)}

Spermatozoal response to HOST were classified three types, strongly coiled, 
moderately coiled and tip coiled and their percentage of incidence were $10.3 \pm 0.97 \% \mathrm{Vs}$ $35.46 \pm 0.68,11.6 \pm 1.38$ Vs $24.26 \pm 1.21 \%$ and $42.7 \pm 2.33 \mathrm{Vs} 15.5 \pm 0.99 \%$, respectively (Table 1). The strongly coiled spermatozoa were very low in the present study compared to fertile dogs. On the contrary, the tip coiled spermatozoa were high in the present study.

\section{Biochemical characteristics of semen}

The Total protein, albumin and globulin level in the seminal plasma of different breeds of dogs were $2.47 \pm 0.29 \mathrm{~g} / \mathrm{dl}, 0.28 \pm 0.05 \mathrm{~g} / \mathrm{dl}$ and $1.96 \pm 0.24 \mathrm{~g} / \mathrm{dl}$, respectively. The alkaline and acid phosphatase level in the seminal plasma was $1904 \pm 329 \mathrm{IU} / \mathrm{L}$ and $925 \pm 79.0$ IU/L, respectively in breeds of dogs (Table 2). The ALP and ACP level in the seminal plasma were low in the present study compare to other reports on fertile dog semen.

Based on Breeding Soundness Examination, the biophysical and biochemical characteristics of semen were significantly low in the present study. Among the nine dogs subjected to BSE, all the dogs were infertile.

Among the infertile dogs the incidence of detached sperm head and distal cytoplasmic droplets were predominant (Fig. 2 and 3).
The percentage of incidence of dead spermatozoa, HOS negative, acrosome defects were high for infertile dogs. In both infertile dogs the incidences of abnormal spermatozoa were within permissible level, but however detached sperm head and distal cytoplasmic droplets were predominant in infertile dogs (Fig. 2 and 3).

The various poor semen quality parameters among infertile dogs observed and identified in this study were Aspermia (Fig. 4), Azoospermia, Oligo and hypokinozoospermia and poor membrane integrity of spermatozoa.

The epididymal secretary functions are largely reflected by ALP level in the seminal plasma and they were very low in all infertile dogs compared to fertile dog's semen.

Infertile dogs comprised of nine dogs (GSD; $\mathrm{n}=1$, Labrador; $\mathrm{n}=2$, pug; $\mathrm{n}=3$, Golden Retriever; $n=1$, Cocker spaniel; $n=1$ and Spitz; $\mathrm{n}=1$ ). In infertile dogs, the testes were soft in texture and no other scrotal abnormality was noticed.

The semen was collected at weekly intervals for six consecutive weeks but Aspermia constitute $32 \%$ and the remaining ejaculate were analyzed and compared.

Fig.1 Measurement of testicular volume

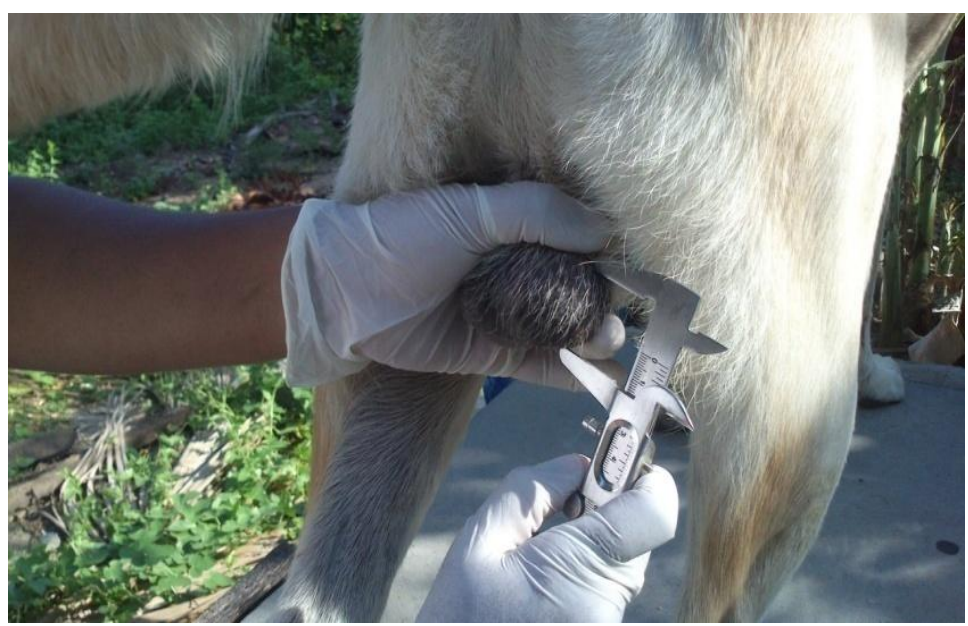


Fig.2 Detached sperm head; Eosin-nigrosin stain (1000x magnification)

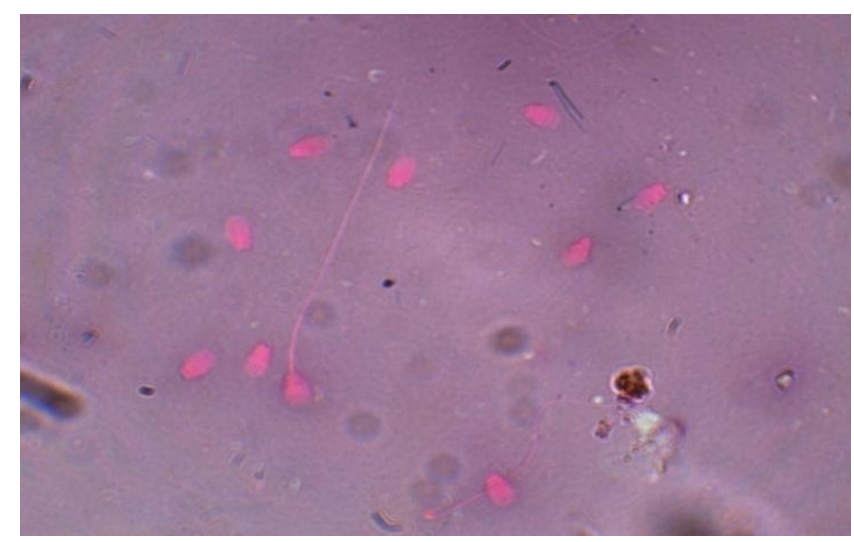

Fig.3 Distal cytoplasmic droplet; Eosin-nigrosin stain (1000x magnification)

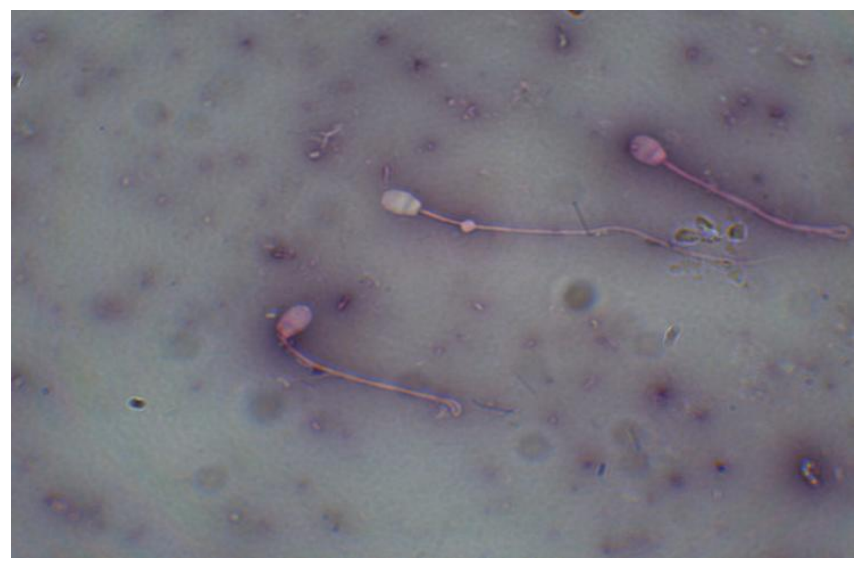

Fig.4 Percentage of incidence of Aspermia in different breeds of infertile dogs

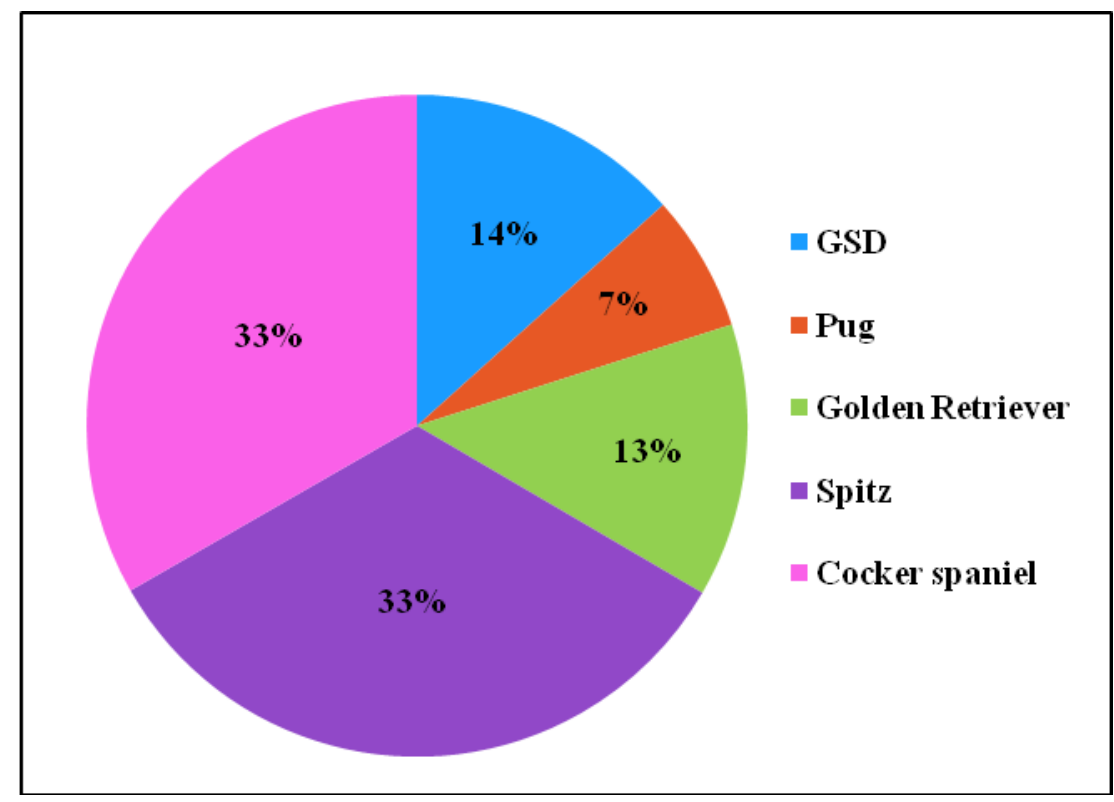


Table.1 Semen characteristics in different breeds of dogs

\begin{tabular}{|c|c|c|c|c|c|c|c|}
\hline & \multirow[b]{2}{*}{ Parameters } & \multirow[b]{2}{*}{ GSD } & \multirow[b]{2}{*}{ Labrador } & \multicolumn{2}{|c|}{ Breeds in dog } & \multirow[b]{2}{*}{ Spitz } & \multirow[b]{2}{*}{ Cocker spaniel } \\
\hline SI. No & & & & Pug & Golden Retriever & & \\
\hline 1 & BCS & $3.00 \pm 0.00$ & $6.00 \pm 0.30^{b}$ & $4.33 \pm 0.45^{\mathrm{c}}$ & 3 & 3 & 2 \\
\hline 2 & Testicular volume $\left(\mathrm{cm}^{3}\right)$ & $24.5 \pm 0.00^{\mathrm{a}}$ & $35.2 \pm 1.71^{\mathrm{b}}$ & $13.7 \pm 0.32^{\mathrm{c}}$ & 14.05 & 26.4 & 6.14 \\
\hline 3 & Volume of the semen (ml) & $5.00 \pm 0.57^{\mathrm{a}}$ & $5.95 \pm 0.57^{\mathrm{ac}}$ & $1.97 \pm 0.18^{b}$ & $1.92 \pm 0.07$ & 4.50 & 3 \\
\hline 4 & Colour of the semen & Clear & Opalescent & Clear/Opalescent & Clear & Clear & Clear \\
\hline 5 & $\mathrm{pH}$ of the semen & $5.50 \pm 0.00^{\mathrm{a}}$ & $6.25 \pm 0.07^{b c}$ & $6.20 \pm 0.06^{\mathrm{c}}$ & $5.75 \pm 0.14$ & 6.50 & 5.50 \\
\hline 6 & Mass Activity of spermatozoa & $2.00 \pm 0.00^{\mathrm{a}}$ & $3.00 \pm 0.00^{b}$ & $2.40 \pm 0.19^{\mathrm{ac}}$ & Azoospermia & 3 & Azoospermia \\
\hline 7 & Initial Motility of spermatozoa (\%) & $20.0 \pm 0.00^{\mathrm{a}}$ & $78.3 \pm 1.12^{b}$ & $45.3 \pm 4.86^{\mathrm{c}}$ & Azoospermia & 80 & Azoospermia \\
\hline 8 & Sperm Concentration (millions/ml) & $20.0 \pm 0.00^{\mathrm{ac}}$ & $210 \pm 22.0^{b}$ & $55.2 \pm 16.2^{\mathrm{c}}$ & Azoospermia & 328 & Azoospermia \\
\hline 9 & Live Spermatozoa (\%) & $57.7 \pm 2.49^{\mathrm{ac}}$ & $83.1 \pm 2.27^{b}$ & $63.2 \pm 3.20^{\mathrm{c}}$ & Azoospermia & 93 & Azoospermia \\
\hline 10 & Total sperm Abnormality (\%) & $2.00 \pm 0.40$ & $8.29 \pm 1.94$ & $15.8 \pm 3.58$ & Azoospermia & 90 & Azoospermia \\
\hline 11 & Intact Acrosome (\%) & $8.70 \pm 0.85^{\mathrm{ac}}$ & $58.6 \pm 4.32^{b}$ & $30.0 \pm 6.00^{c}$ & Azoospermia & 72 & Azoospermia \\
\hline 12 & $\operatorname{HOS}(+)(\%)$ & $3.00 \pm 0.40^{\mathrm{ac}}$ & $53.4 \pm 4.76^{\mathrm{b}}$ & $29.3 \pm 6.43^{c}$ & Azoospermia & 70 & Azoospermia \\
\hline
\end{tabular}

Mean value having different super script within row differ significantly $(\mathrm{P}<0.05)$.

GSD - Two collections are Aspermia.

Pug - Three collections are Aspermia.

Golden Retriever - Two collections are Aspermia.

Spitz - Five collections are Aspermia.

Cocker spaniel - Five collections are Aspermia.

Table.2 Seminal plasma biochemical parameters in different breeds of dogs

\begin{tabular}{|c|c|c|c|c|c|c|c|}
\hline \multirow[t]{2}{*}{ SI. No } & \multirow[t]{2}{*}{ Parameters } & \multicolumn{6}{|c|}{ Breeds in dogs } \\
\hline & & GSD & Labrador & Pug & Golden Retriever & Spitz & Cocker spaniel \\
\hline 1 & Total Protein $(\mathrm{g} / \mathrm{dl})$ & $1.52 \pm 0.24^{\mathrm{ac}}$ & $3.66 \pm 0.53^{b}$ & $1.72 \pm 0.26^{\mathrm{c}}$ & $1.47 \pm 0.29$ & 3.10 & 1.90 \\
\hline 2 & Albumin (g/dl) & $0.17 \pm 0.02$ & $0.38 \pm 0.12$ & $0.24 \pm 0.04$ & $0.32 \pm 0.13$ & 1.40 & 0.90 \\
\hline 4 & ALP (IU/L) & $1544 \pm 587.7$ & $2568 \pm 185.3$ & $1468 \pm 631.5$ & $172.8 \pm 109.6$ & 1806 & 2322 \\
\hline 5 & ACP (IU/L) & $1341 \pm 37.81$ & $935.7 \pm 120.3$ & $807.5 \pm 119.3$ & $25.00 \pm 6.45$ & 213 & 230.0 \\
\hline
\end{tabular}

Mean value having different super script within row differ significantly $(\mathrm{P}<0.05)$. 
The mean body condition score for all infertile dogs was $4.80 \pm 0.32$. The mean testicular volume, volume of the ejaculate and $\mathrm{pH}$ of semen $(23.4 \pm 1.94,3.90 \pm 0.42 \mathrm{ml}$ and $6.12 \pm 0.06$ ) were low in infertile dogs compared to fertile dogs. The BCS and testicular volume did not differ between weeks of evaluation in infertile dogs. Costa et al., (2010) and Singh et al., (2014) reported that as the body weight increased, the scrotal circumference also increased without parallel increase in testicular volume and sperm concentration.

In infertile dogs, seven out of nine infertile dogs gave clear and colourless ejaculate consistently. The remaining two dog ejaculates were opalescent throughout the study period and confirmed as normospermia. The dogs that gave clear and colourless ejaculates were confirmed as oligozoospermia in four dogs, azoospermia in one dog and the remaining two dogs were Aspermia.

The mean sperm concentration for all infertile dogs was $110.0 \pm 18.52$ millions / $\mathrm{ml}$. The sperm concentration was low in infertile dogs compared to fertile dog semen. The testicular volume $\left(23.4 \pm 1.94 \mathrm{~cm}^{3}\right)$ and sperm concentration $(110.0 \pm 18.52$ millions / ml) were low in infertile dogs compared to fertile dogs. The sperm concentration in the ejaculate depended on testicular size and extragonadal sperm reserve (Amann, 1981 and Olar et al., 1983).

In all oligozoospermic dogs, the spermatozoa showed hypokinozoospermia which was different from that of fertile dogs (54.8 \pm $4.39 \%$ initial motility and $2.58 \pm 0.11$ mass activity).

The alkaline phosphatase level in the seminal plasma was also less in infertile dogs. The ALP in the seminal plasma is a biochemical marker for epididymal function (Strzezek et al., 2015). Hence in this study, in normospermic dogs the epididymal dysfunction could be the cause for infertility.

Among the infertile dogs the incidence of detached sperm head and distal cytoplasmic droplets were predominant whereas, tail abnormalities were common. The higher incidence of detached sperm head and distal cytoplasmic droplet indicated possible testicular and epididymal dysfunction. Ortega-Pacheco et al., (2006b) reported that detached heads are common sperm abnormalities in canine testicular degeneration. Barth and Oko (1989) recorded that cytoplasmic droplets indicate pathological conditions of the epididymis.

The percentage of incidence of intact acrosome and HOS positive sperms were low in infertile dogs compared to fertile dogs. The percentage of intact acrosome was $38.3 \pm 4.58 \%$ and HOS positive spermatozoa were $35.2 \pm 4.67 \%$ for infertile dogs. The acrosome integrity was classified as intact acrosome (38.3 $\pm 4.58 \%)$, partially lost acrosome $(23.9 \pm 3.48 \%)$ and completely lost acrosome $(37.7 \pm 4.47 \%)$. Based on the type of sperm swelling the HOS positive sperms were classified as strongly coiled $(10.3 \pm 0.97 \%)$, moderately coiled (11.6 \pm $1.38 \%)$ and tip coiled $(42.7 \pm 2.33 \%)$. The strongly coiled tail was low in infertile dogs compared to fertile dogs. On the contrary the incidence of tip coiling was high in infertile dogs. Hence from the study it can be conclude that there was poor in the permeability of plasma membrane and acrosome integrity in infertile dogs.

In infertile dogs the total protein, albumin and globulin were $2.47 \pm 0.29 \mathrm{~g} / \mathrm{dl}, 0.28 \pm 0.05 \mathrm{~g} / \mathrm{dl}$ and $1.96 \pm 0.24 \mathrm{~g} / \mathrm{dl}$, respectively and the values were not different from fertile dogs. The ALP and ACP level in the seminal plasma were low in infertile dogs compared to 
fertile dogs. The ALP and ACP levels were $1904 \pm 329$ Vs $925 \pm 79.0$ in infertile. Hence, the low level of ALP and ACP could be due to secretary dysfunction of epididymis and prostate gland, since both ALP and ACP were the biochemical markers for the functional integrity of epididymis and prostate gland respectively.

On enquiry from dog owners all the infertile dogs had mated previously during two breeding seasons with no resultant pregnancy. Infertile dogs were systematically screened for BSE and all the semen quality measures comparable to other reports on the fertile dog semen (Gunay et al., 2003; Kurien et al., 2012; Domoslawska et al., 2013). The various poor semen quality parameters among infertile dogs observed and identified in this study were Aspermia, Azoospermia, Oligo and hypokinozoospermia and poor membrane integrity of spermatozoa. The epididymal and prostate secretary functions are largely reflected by ALP and ACP level in the seminal plasma and they were very low compared to fertile dog semen. Hence it can be concluded that the epididymal and prostate secretary functions were also poor.

\section{References}

Amann, R.P., 1981. A critical review of methods for evaluation of spermatogenesis from seminal characteristics. J. Androl., 2: 37-58.

Barth, A.D., and Oko, R.J. 1989. Abnormal morphology of bovine spermatozoa. Ames: Iowa State University Press, 285.

Costa, G.M., Leal, M.C., Silva, J.V., Ferreira, A.C.S., Guimaraes, D.A. and Franca, L.R. 2010. Spermatogenic cycle and sperm production in a fetal pig species. J. Androl.31: 221-230.

Domosławska, A., Sławomir Zduńczy, K., Wojciech Niżańskil, and Tomasz Janowski. 2013. Assessment of semen quality in infertile dogs using computerassisted sperm analysis by the Hamilton-Thorne Semen Analyser. Bull. Vet. Inst. Pulawy., 57: 429-432.

Edney, A.T.B., and Smith, P.M. 1986. Study of obesity in dogs visiting veterinary practices in the United Kingdom. Vet. Rec, 118: 391-396.

Gunay, U., Polat, U., Gunes, N., Soylu, M.K., and Kil, F. 2003. The effects of shortinterval ejaculation on semen quality and some biochemical parameters in dogs. Revue. Med. Vet, 154: 459-62.

Hafez, E.S.E., 1993. Reproduction in farm animals. Semen evaluation, Lea and Febiger, Pp. 405-423.

Harriet, J.P., Diamond, D.A., Canzio, J.D., Zurakowski, D., Borer, J.G., and Atala, A. 2002. Testicular volume: Comparison of orchidometer and US measurements in dogs. Radiology, 22: 114-119.

King, G.J., and Macpherson, J.W. 1966. Alkaline and acid phosphatase activity, $\mathrm{pH}$ and osmotic pressure of boar semen. Canadian Journal of Comparative Medicine and Veterinary Science, 30:304-307.

Kurien, M.O., Katheresan, D., Atheresan, Selvaraju, M., Elvaraju, and Pattabiraman, S.R. 2012. Macroscopic, microscopic and bio-chemical characteristics of fresh dog semen. Indian Journal of Animal Reproduction, 33(1):18-20.

Laflamme, D.P. 1997. Development and validation of a body condition score system for Dogs. Canine Practice, 22:10-15.

Linde Forsberg, C. 2005a. Artificial Insemination. In ESAVS-EVSSAR course reproduction in companion, exotic and laboratory animal, Nantes $12^{\text {th }}-17^{\text {th }}$ September.

Olar, T.T., Amann, R.P., and Pickett, B.W. 1983. Relationships among testicular 
size, daily production and output of spermatozoa and extragonadal spermatozoa reserves of the dog. Biol. Reprod., 29: 1114-1120.

Ortega-Pacheco, A., Segura-Correa, J.C., Bolio Gonzalez, M.E., Jiménez-Coello, M., and Linde Forsberg, C. 2006 b. Reproductive patterns of stray males dogs in the tropics. Theriogenology, 66: 2084-2090.

Schafer-Somi, S., Frohlich, T., and Schwendenwein, I. 2013. Measurement of alkaline phosphatase in canine seminal plasma. Reprod. Domest. Anim, 48: $10-12$.

Silva, L.D.M., Souza, M.B., Barbosa, C.C., Pinto, J.N., Uchoa, D.C., and Campello, C.C. 2012. Comparison of testicular volume between French Bulldog and Brazilian Terrier dog. Proceedings of the 7th International Symposium on
Canine and Feline Reproduction ISCFR, Whistler, Canada.

Sing, A.K., Bare, P.S., and Cheema, R.S. 2014. Relationship among frozenthawed semen fertility, physical parameters, certain sperm characteristics and testosterone in breeding murrah buffalo (Bubalus bubalis) bulls. Veterinary world, 7: 644.

Strzeżek, R., Koziorowska-Gilun, M. Kiełczewski, K., and Kordan, W. 2015. Effect of dialysis of $\operatorname{dog}$ semen on sperm characteristics and some biochemical components of seminal plasma. J. Vet. Sci, 18: 447-448.

Wells, M.E., and Awa, O.A. 1970. New technique for assessing acrosomal characteristics of spermatozoa. J. Dairy. Sci., 53: 227-232.

\section{How to cite this article:}

Shalini, I., D. Antoine, K. Murugavel, S. Kantharaj and Raju, M.S. 2018. Testicular Volume, Seminal Attributes and Body condition score in Infertile Dogs. Int.J.Curr.Microbiol.App.Sci. 7(06): 455-464. doi: https://doi.org/10.20546/ijcmas.2018.706.051 